Jurnal MeA (Media Agribisnis), 4(2), Oktober 2019, pp.76-83

Media Komunikasi Hasil Penelitian Bidang IImu Agribisnis

ISSN 2548-7027 (Print) | ISSN 2541-6898 (Online)

DOI $10.33087 /$ mea.v4i2.53

\title{
KONTRIBUSI PENDAPATAN USAHATANI TANAMAN SELA DALAM MERINGANKAN BIAYA PRODUKSI TANAMAN KELAPA SAWIT MUDA KECAMATAN MUARO JAMBI DI KABUPATEN MUARO JAMBI
}

\author{
Siti Abir Wulandari \\ Dosen Program Studi Agribisnis, Fakultas Pertanian Universitas Batanghari \\ J1. Slamet Riyadi-Broni, Jambi. 36122. Telp. +6274160103 \\ email: abir_wulandari@yahoo.com
}

\begin{abstract}
One of the policies of the Jambi Province plantation sector is the rejuvenation of oil palms with an area as 15,177 ha. According to the government's program, the target ofthis program in 2018 wouldtake 20 thousand hectares that spreaded over six districts namely Muaro Jambi, Batanghari, Tanjung Jabung Barat, Bungo, Merangin and Tebo. The oil palm rejuvenation program wasconducted through a grant of Rp. 25 million per hectare and the remainder was funded by a bank. This assistance came from the Ministry of Finance through the Fund Management Agency (BPDP). While waiting the gestation period of oil palm, the farmers were encouraged to apply intercropping farm system in it. This study aimed to calculate the total costs both of oil palm farming, and for intercropping farming, to calculate intercropping farming income, calculated the contribution of intercropping to cover the palm oil farming costs. This research was carried out in Sungai Bahar District, Muaro Jambi Regency. The location was chosen because it was the first place for oil palm planting in Jambi Province. Therefore, this District became aleader for the former oil palm smallholder (PIR-Trans) in rejuvenating throughout Jambi Province. The type of data collected based on time was cross section (a certain time), and the type of data base on the scale was ratio. The data used was obtained from both primary and secondary data. The Obtained data were simplified by tabulation and percentages, then it was analyzed descriptively. Thenproceed with income analysis of oil palm and intercroppingfarming. The results showed thatthe total costs needed oil palm farming in the firsh 5 years was Rp. 73,410 / ha / month with an average land area of 2.8 hectares. The cost required for intercropping farming was $R p .289,079$ / ha / month. Average of inter-crop farming income was Rp. 7,139,003 / ha / month. Income of intercropping farming contributed $1.953 \%$ to cover the costs of oil palm farming because all of it operational costs was covered by this intercropping income.
\end{abstract}

Keywords : Farming, Oil palm, Replanting, intercropping

Diterbitkan oleh Program Studi Agribisnis Fakultas Pertanian Universitas Batanghari Jambi Halaman 76 


\begin{abstract}
Abstrak
Salah satu kebijakan sektor perkebunan Provinsi Jambi adalah peremajaan kelapa sawit dengan luas replanting kelapa sawit adalah 15.177 ha. Sesuai program pemerintah pusat, target peremajaan kelapa sawit di Propinsi Jambi pada tahun 2018 seluas 20.000 ha. Tersebar di enam kabupaten yakni Muaro Jambi, Batanghari, Tanjung Jabung Barat, Bungo, Merangin dan Tebo (Dinas Perkebunan Propinsi Jambi, 2019). Program peremajaan tanaman kelapa sawit diupayakan melalui bantuan dana hibah sebesar $\mathrm{Rp} 25$ juta per hektare dan sisanya didanai kredit perbankan. Bantuan ini berasal dari Kementerian Keuangan melalui Badan Pengelola Dana Perkebunan (BPDP) Kelapa Sawit. Selain itu petani dianjurkan untuk melakukan usahatani tanaman sela selama masa tunggu kelapa sawit berproduksi (Kemenperin, 2019). Penelitian ini bertujuan untuk menghitung besar biaya usahatani kelapa sawit dan usahatani tanaman sela, menghitung pendapatan usahatani tanaman sela serta menghitung besar kontribusi tanaman sela untuk menutupi biaya tanaman kelapa sawit. Penelitian ini di laksanakan di Kecamatan Sungai Bahar Kabupaten Muaro Jambi, dipilihnya lokasi penelitian ini karena Kecamatan Sungai Bahar merupakan tempat penanaman kelapa sawit pertama di Provinsi Jambi oleh sebab itu Kecamatan Sungai Bahar menjadi contoh bagi petani eks Perkebunan Inti Rakyat (PIR-Trans) dan petani plasma dalam melakukan peremajaan di seluruh Provinsi Jambi. Jenis data yang di kumpulkan dalam penelitian ini berdasarkan waktu adalah jenis data cross section (satu waktu tertentu), dan jenis data menurut skala pengukuran adalah data rasio. Sumber data yang digunakan berasal daridata primer dan data sekunder. Data yang diperoleh dari hasil penelitian disederhanakan dengan cara tabulasi dan persentase, kemudian dianalisis secara deskriptif. Kemudian dilanjutkan dengan analisis pendapatan usahatani kelapa sawit dan tanaman sela. Dari hasil di atas maka dapat disimpulkan bahwa :Biaya yang dibutuhkan untuk usahatani kelapa sawit usia muda yaitu sebesar Rp. 73.410 /ha/bln denga rata-rata luas lahan 2,8 Ha. Biaya yang dibutuhkan untuk usahatani tanaman sela yaitu sebesar Rp. 289.079/ha/bln.Rata-rata pendapatan usahatani tanaman sela yaitu sebesar Rp 7.139.003/ha/bln. Pendapatan usahatani tanaman sela berkontribusi $1.953 \%$ dalam untuk menutupi biaya tanaman kelapa sawit karena seluruh biaya operasional tanaman kelapa sawit muda tertutupi oleh pendapatan tanaman sela.
\end{abstract}

Kata Kunci : Usahatani, Kelapa sawit, Replanting, Tanaman sela

\title{
PENDAHULUAN
}

Kelapa sawit merupakan salah satu komoditas perkebunan yang diunggulkan dan memegang peranan penting dalam perekonomian masyarakat Jambi. Pada tahun 2018 luas perkebunan kelapa sawit Provinsi Jambi 791.025 Ha, dominasi Perkebunan rakyat 66,66 \%, Perkebunan Negara 3,01 \%, Perkebunan Swasta 30,33 \%. Penyumbang $17.2 \%$ dari Total PDRB Provinsi Jambi. Salah satu hambatan sektor perkebunan adalah rendahnya produktivitas tanaman karena 
banyak tanaman tua (usia di atas 20 thn) (Dinas Perkebunan Provinsi Jambi, 2019).

Salah satu kebijakan sektor perkebunan Provinsi Jambi dalam upaya meningkatkan produktivitas tanaman kelapa sawit adalah peremajaan kelapa sawit dengan luas replanting kelapa sawit adalah 15.177 ha. Sesuai program pemerintah pusat, target peremajaan kelapa sawit di Propinsi Jambi pada tahun 2018 seluas 20 ribu hektar. Tersebar di enam kabupaten yakni Muaro Jambi, Batanghari, Tanjung Jabung Barat, Bungo, Merangin dan Tebo. (Dinas Perkebunan Provinsi Jambi, 2019). Program peremajaan tanaman sawit diupayakan melalui bantuan dana hibah sebesar Rp 25 juta per hectare dan sisanya didanai kredit perbankan. Selain itu petani dianjurkan untuk melakukan usahatani tanaman sela selama masa tunggu kelapa sawit berproduksi. (Kemenperin, 2019).

Replanting tanaman kelapa sawit merupakan peluang untuk memproduksi tanaman pangan seperti padi ladang, kedelai, jagung serta tanaman hortikultura lainnya yang bisa menjadi penghasilan keluarga tani sebelum tanaman kelapa sawit menghasilkan.Replanting kelapa sawit dirasakan melambat dikarenakan petani takut kehilangan penghasilan keluarga, walaupun secara ekonomis tanaman kelapa sawit tidak lagi menguntungkan dan hanya beberapa petani saja yang mau melakukan tumpang sari tersebut.

Program pemerintah terhambat karena petani tidak mau melakukan peremaajan. Petani merasa khawatir tidak memperoleh pendapatan selama hampir 4-5 tahun masa tunggu kelapa sawit berproduksi meskipun akan ada usahatani sampingan (tanaman sela) dan bantuan dana hibah. Dinas Perkebunan Provinsi Jambi dan dinas vertikalnya di kabupaten/ kota harus bekerja ekstra meyakinkan petani kelapa sawit bahwa program peremajaan kelapa sawit ini menguntungkan.

Tujuan dari penelitian ini adalah untuk menghitung besar biaya usahatani kelapa sawit dan usahatani tanaman sela, pendapatan usahatani tanaman sela, besar kontribusi tanaman sela untuk menutupi biaya tanaman kelapa sawit.

\section{METODOLOGI PENELITIAN}

Penelitian ini di laksanakan di Kabupaten Muaro Jambi, dipilihnya lokasi penelitian ini karena merupakan tempat penanaman kelapa sawit pertama di Provinsi Jambi oleh sebab itu wilayah Sungai Bahar menjadi contoh bagi petani eks Perkebunan Inti Rakyat (PIR-Trans) dan petani plasma dalam melakukan peremajaan di seluruh Provinsi Jambi. Ruang lingkup penelitian ini dibatasi pada perbandingan pendapatan usahatani kelapa sawit usia tua dengan usahatani tanaman sela.

Jenis data yang di kumpulkan dalam penelitian ini berdasarkan waktu adalah jenis data cross section (satu waktu tertentu), dan jenis data menurut skala pengukuran adalah data rasio. Sumber data yang digunakan berasal dari data primer dan data sekunder. Data primer di peroleh melalui penyebaran kuisioner terhadap responden yaitu petani kelapa sawit di Kecamatan Bahar Utara dan Kecamatan Bahar Tengah Kabupaten Muaro Jambi, Data sekunder merupakan data penunjang data primer yang diperoleh dari instansi terkait berupa laporan, 
jurnal-jurnal penelitian, dan publikasi yang mendukung penelitian ini. Data sekunder dikumpulkan dengan menggunakan studi kepustakaan.

Penelitian ini dilakukan dengan menggunakan metode survei. Menurut Nazir (2014), metode survei merupakan penyelidikan yang diadakan untuk memperoleh fakta-fakta dari gejala-gejala yang ada dan mencari keteranganketerangan secara faktual. Teknis pelaksanaan dilakukan dengan observasi dan wawancara, pengisian kuisioner dan pengumpulan data sekunder. Penyelidikan dilakukan dalam waktu yang bersamaan dengan melibatkan beberapa individu yang dijadikan responden. Dalam penelitian survei dengan kuisioner di perlukan responden dalam jumlah yang cukup agar validitas temuan tercapai dengan baik (Irawan, 2007 dalam Prayudi Yusuf, 2009).

Populasi sekaligus berstatus sampel adalah semua petani kelapa sawit yang melakukan replanting sekaligus yang menanam tanaman sela di wilayah tersebut. Karena jumlah petani kelapa sawit yang melakukan replanting sekaligus yang menanam tanaman sela sedikit yaitu sebanyak masing 30 orang untuk setiap usahatani kelapa sawit dan tanaman sela, maka semua sampel diambil menggunakan metode sensus.

Data yang diperoleh dari hasil penelitian disederhanakan dengan cara tabulasi dan persentase, kemudian dianalisis secara deskriptif. Kemudian dilanjutkan dengan analisis pendapatan usahatani kelapa sawit dan tanaman sela.

Untuk mengetahui penggunaan input dan biaya produksi yang digunakan dalam usahatani kelapa sawit dan tanaman sela dianalisis secara deskriptif, untuk menghitung besarnya jumlah biaya produksi dengan cara menjumlahkan total biaya tetap atau total fixed cost (TFC) dalam rupiah per bulan, ditambah total biaya tidak tetap atau total variable cost (TVC) dalam rupiah per bulan, sesuai dengan rumus Sudarman dan Algifari (2001):

$\mathrm{TC}=\mathrm{TFC}+\mathrm{TVC}$

Keterangan:

$\mathrm{TC}=$ Total Biaya atau Total Cost (Rp/Bulan).

TFC = Total Biaya Tetap atau Total Fixed Cost (Rp/Bulan).

$\mathrm{TVC}=$ Total Biaya Variabel atau Total Variabel Cost (Rp/Bulan).

Untuk menghitung besarnya penerimaan ditentukan dengan menggunakan rumus sebagai berikut ( Samuelson dan Nordhaus, 2003):

$\mathrm{TR}=\mathrm{Pq} \cdot \mathrm{Q}$

Keterangan:

$\mathrm{TR}=$ Total Penerimaan atau Total Revenue (Rp/Bulan).

$\mathrm{Pq} \quad=$ Harga Produk $(\mathrm{Rp} / \mathrm{Kg})$.

$\mathrm{Q} \quad=$ Jumlah Produksi kering atau basah (Kg/Bulan).

Untuk menghitung besarnya biaya penyusutan alat digunakan rumus (Syafri, 2002). Dengan asumsi harga akhir alat sebesar nol : 
$\mathrm{D}=\frac{\mathrm{P}-\mathrm{S}}{\mathrm{N}}$

Keterangan:

$\mathrm{D}=$ Biaya Penyusutan Alat (Rp/Bulan).

$\mathrm{P} \quad=$ Harga awal alat $(\mathrm{Rp})$.

$\mathrm{S} \quad=$ Harga akhir alat (Rp).

$\mathrm{N} \quad=$ Perkiraan Umur Ekonomis (Bulan).

Untuk mengetahui pendapatan diperoleh dengan cara mengurangkan total penerimaan dengan total biaya, dengan rumus sebagai berikut (Boediono, 1992):

$\mathrm{I}=\mathrm{TR}-\mathrm{TC}$

Keterangan:

I $\quad=$ Pendapatan atau Income $(\mathrm{Rp} /$ Bulan $)$.

$\mathrm{TR}=$ Total Penerimaan atau Total Revenue (Rp/Bulan).

$\mathrm{TC}=$ Total Biaya atau Total Cost (Rp/Bulan).

\section{Karakteristik Petani}

\section{Umur Petani}

Umur atau usia adalah waktu atau masa hidup seseorang selama masih hidup di dunia yang dihitung mulai dari manusia itu dilahirkan. Tingkat umur berpengaruh tinggi terhadap tingkat kemampuan petani dalam melaksanakan kegiatan. Selain itu umur juga dapat mempengaruhi pola berpikir dalam pengambilan keputusan yang berkaitan dengan kegiatan yang akan dilaksanakan (Soekartawi, 2011). Subri, M (2003) mendefinisikan tenaga kerja adalah penduduk dalam usia kerja produktif (berusia 15-64 tahun) atau jumlah seluruh penduduk dalam suatu negara yang dapat memproduksi barang dan jasa. Semakin muda umur petani biasanya lebih bersemangat untuk ingin tahu apa yang belum pernah mereka ketahui sehingga mereka berusaha untuk lebih cepat melakukan inovasi dalam berusahatani.

Hasil penelitian menunjukan bahwa di daerah penelitian kisaran umur petani umumnya bervariasi yaitu untuk umur petani kelapa sawit kisaran 34-80 tahun, sedangkan rata-rata umur petani kelapa sawit adalah 46 tahun. Dan untuk umur petani tanaman sela kisaran 29-57 tahun, dengan rata-rata umur petani tanaman sela adalah 38 tahun.

\section{Luas Lahan}

Tanah adalah pabrik hasil pertanian, tempat proses produksi berjalan selanjutnya menghasilkan produk pertanian (Mubyarto,1986). Luas lahan yang dimiliki oleh petani akan sangat menentukan pendapatan yang akan diterima oleh petani. Dari hasil penelitian dilapangan menunjukan bahwa rata-rata petani kelapa sawit memiliki luas lahan antara 3 ha. Sedangkan rata-rata petani tanaman sela memiliki luas lahan 2 ha. 


\section{Pendidikan}

Pendidikan petani adalah hal yang sangat penting dalam kehidupan sebagai dasar untuk memperoleh pengetahuan dan keterampilan. Pendidikan petani pada penelitian ini diukur berdasarkan tingkat pendidikan formal yang pernah ditempuhnya. Tingkat pendidikan petani akan mempengaruhi cara berpikir, menerima dan mencoba hal-hal yang baru. Tingkat pendidikan seseorang dapat mengubah pola pikir, daya penalaran yang lebih baik, sehingga makin lama seseorang mengenyam pendidikan akan makin rasional. Tingkat pendidikan petani kelapa sawit adalah tamat SD sedangkan untuk petani tanaman sela adalah tamatan SPM dan SMA.

\section{Jumlah Anggota Keluarga}

Hernanto (1979), menyatakan bahwa jumlah anggota keluarga berpengaruh terhadap pengolahan suatu usahatani yang dijalankan, khususnya terhadap ekonomi pada usahatani tersebut.Tanggungan keluarga merupakan salah satu faktor yang mempengaruhi keberhasilan berusahatani, semakin banyak jumlah tanggungan keluarga maka semakin banyak kebutuhan yang akan dipenuhi oleh petani. Rata-rata jumlah anggota keluarga petani kelapa sawit dan petani tanaman sela adalah sebanyak 3 orang.

\section{Biaya Tetap Dan Biaya Variabel}

Biaya tetap(fixed cost) yang dihitung pada penelitian ini biaya yang dikeluarkan berdasarkan biaya penyusutan alat-alat yang termasuk biaya tetap petani kelapa sawit dalam penelitian ini adalah cangkul, parang, angkong, golok, dan yang termasuk biaya tetap petani tanaman sela adalah cangkul, parang. Biaya variabel (variable cost) yang dihitung penelitian ini adalah biaya yang berubahubah sesuai dengan perubahan output, yang termasuk biaya variabel petani kelapa sawit adalah SP-36, urea, dan dolomit. Sedangkan untuk biaya variabel petani tanaman sela adalah NPK, urea, dan dolomit. Rata-rata biaya tetap petani kelapa sawit berjumlah $\mathrm{Rp} 9.557 / \mathrm{ha} / \mathrm{bln}$, rata-rata biaya variabel yang dikeluarkan berjumlah $\mathrm{Rp} 63.853 / \mathrm{ha} / \mathrm{bln}$, dan rata-rata biaya tetap petani tanaman sela berjumlah Rp.6.829/ha/bln. Sedangkan rata-rata biaya variabel yang dikeluarkan berjumlah Rp. 282.250/ha/bln. Jumlah total biaya keseluruhan dari petani kelapa sawit dan tanaman sela adalah sebesar Rp. 365.489/ha/bln. Untuk lebih jelasnya dapat dilihat pada Tabel 1 berikut ini: 


\begin{tabular}{|c|c|c|c|c|c|c|}
\hline \multirow[b]{2}{*}{ No } & \multicolumn{3}{|c|}{ Kelapa Sawit } & \multicolumn{3}{|c|}{ Tanaman Sela } \\
\hline & Uraian & $\begin{array}{c}\text { Jumlah } \\
\text { (Rp/Bulan) }\end{array}$ & $\begin{array}{c}\text { Persentase } \\
(\%)\end{array}$ & Uraian & $\begin{array}{c}\text { Jumlah } \\
\text { (Rp/Bulan) }\end{array}$ & $\begin{array}{c}\text { Persentase } \\
(\%)\end{array}$ \\
\hline \multirow[t]{5}{*}{1} & Biaya Tetap & 9.557 & 13,02 & Biaya Tetap & 6.829 & 2,36 \\
\hline & - Cangkul & 2.896 & 3,94 & - Cangkul & 4.863 & 1,68 \\
\hline & - Parang & 1.135 & 1,54 & - Parang & 1.966 & 0,68 \\
\hline & - Angkong & 4.933 & 6,72 & - & - & - \\
\hline & - Golok & 592,82 & 0,82 & - & - & - \\
\hline \multirow[t]{5}{*}{2} & $\begin{array}{l}\text { Biaya Tidak } \\
\text { Tetap }\end{array}$ & 63.853 & 86,98 & $\begin{array}{l}\text { Biaya Tidak } \\
\text { Tetap }\end{array}$ & 282.250 & 97,64 \\
\hline & - $\mathrm{SP}-36$ & 11.753 & 16,01 & - NPK & 106.681 & 36,91 \\
\hline & - Urea & 24.736 & 33,69 & - Urea & 89.528 & 30,97 \\
\hline & - Dolomit & 27.364 & 37,28 & - Dolomit & 86.042 & 29,76 \\
\hline & Jumlah & 73.410 & 100,00 & & 289.079 & 100,00 \\
\hline
\end{tabular}

Sumber : Data Olahan Primer, Tahun 2019

\section{Penerimaan Usahatani Tanaman Sela}

Penerimaan usahatani tanaman sela adalah hasil dari produksi dikali dengan harga jual produk. Besarnya penerimaan tergantung dari harga pada saat produksi dipasarkan. rata-rata produksi usahatani tanaman sela adalah sebanyak 4.252 $\mathrm{Kg} / \mathrm{Ha} /$ bln dengan rata-rata harga jual produksi Rp. $5.126 / \mathrm{kg}$, sehingga diperoleh rata-rata penerimaan sebesar Rp.19.674 Ha/bln.

\section{Pendapatan Usahatani Tanaman Sela}

Indikator keberhasilah usahatani tanaman sela dapat dilihat dari pendapatan yang diterima oleh petani. Pendapatan yang dihitung dalam penelitian ini adalah perkalian antara jumlah hasil produksi dengan harga jual produk dan dikurangi dengan total biaya produksi yang dihitung dalam satuan rupiah per hektar per musim tanam (1 MT= 3 bln). Rata-rata pendapatan yang diterima petani sampel dari usahatani tanaman sela di daerah penelitian adalah sebesar Rp. 19.385.588 MT. Pendapatan petani tersebut jika dikonversi dalam satuan bulan dengan ratarata luas lahan sebesar $2 \mathrm{Ha}$, maka petani akan mendapatkan pendapatan sebesar Rp. 7.139.003/Ha/Bln.

Pendapatan yang dihitung di penelitian ini hanya pendapatan petani tanaman sela karena tanaman kelapa sawit yang baru di replanting belum berproduksi namun sudah mengeluarkan biaya-biaya. Oleh karena itu dengan beban biaya yang semakin besar yaitu biaya operasional tanaman kelapa sawit dan biaya operasional tanaman sela tetap dapat ditanggulangi oleh pendapatan tanaman sela sehingga mampu mengurangi beban petani kelapa sawit yang melakukan kegiatan replanting tanaman kelapa sawit tua. pendapatan usahatani tanaman sela yang telah dikurangi biaya yaitu sebesar Rp. 6.773.514/ha/bln mampu menutupi biaya operasional tanaman kelapa sawit usia muda dan biaya operasional tanaman sela dengan besaran Rp. 365.489/ha/bln. 
Kontribusi pendapatan tanaman sela terhadap biaya tanaman kelapa sawit muda adalah besarnya sumbangan yang diberikan oleh usahatani tanaman sela dalam menutupi biaya tanaman kelapa sawit petani yang dinyatakan dalam persentase (\%). Dalam penelitian ini, diketahui bahwa tanaman sela memberikan kontribusi sebesar $1.953 \%$ dalam manutupi biaya tersebut. Ini mengartikan bahwa tanaman sela layak untuk di usahakan dalam rangka intercorp dengan tanaman kelapa sawit yang di replanting sehingga mampu menutupi biaya usahatani kelapa sawit sebelum menghasilkan kelapa sawit.

\section{KESIMPULAN}

Dari hasil di atas maka dapat disimpulkan bahwa Biaya yang dibutuhkan untuk usahatani kelapa sawit usia muda yaitu sebesar Rp. 73.410 /ha/bln denga rata-rata luas lahan $2 \mathrm{Ha}$, Biaya yang dibutuhkan untuk usahatani tanaman sela yaitu sebesar Rp. 289.079/ha/bln, Rata-rata pendapatan usahatani tanaman sela yaitu sebesar Rp 7.139.003/ha/bln, dan Pendapatan usahatani tanaman sela berkontribusi $1.953 \%$ dalam untuk menutupi biaya tanaman kelapa sawit karena seluruh biaya operasional tanaman kelapa sawit muda tertutupi oleh pendapatan tanaman sela.

\section{DAFTAR PUSTAKA}

Boediono. 1992. Teori Pertumbuhan Ekonomi. BPFE UGM. Yogyakarta

Dinas Perkebunan Provinsi Jambi. 2019. Pembangunan Perkebunan Provinsi Jambi2019.http://jambi.litbang.pertanian.go.id/ind/images/PDF/2018/2018 .04.27-Program-Pembangunan-Perkebunan-Provinsi-Jambi-Tahun-2019. pdf

Hernanto, 1979. Ilmu Usahatani. Penebar Swadaya, Jakarta

Kemenperin. 2019. BPDP Sawit Siap Suntik Dana Replanting https://kemenperin.go.id/artikel/14122/BPDP-Sawit-Siap-Suntik-Dana Replanting

Mubyarto. 1986. Pengantar Ekonomi Pertanian LP3ES. Jakarta.

Nazir. 2014. Metode Penelitian. Ghalia Indonesia. Bogor

Prayudi Yusuf, 2009. Hubungan Kualitas Pelayanan dengan Kepuasan Pengusaha Di Kawasan Berikat pada Kantor Pengawasan dan Pelayanan Bea dan Cukai Tipe A2 Tangerang. http://lib.ui.ac.id/file?file=digital/127082T\%2026329-Hubungan\%20kualitas-HA.pdf

Samuelson, dan Nordhous, 2003. "Ilmu Makro Ekonomi", PT Media Global Edukasi. Jakarta.

Soekartawi, et al. 2011. Usahatani dan Penelitian untuk Pengembangan Petani Kecil. Penerbit UI. Jakarta.

Subri, M. 2003. Ekonomi Sumberdaya Manusia. PT. Raja Grafindo Persada, Jakarta

Syafri. 2002. Analisa Kritis Atas Laporan Keuangan. PT. Raja Grfindo Persada. Jakarta. 